\title{
The Application and Innovation of Crowdsourcing in the Internet Age
}

\author{
Gencheng Li \\ Institute of Industrial Economics, Jinan University, Guangzhou, China \\ Email: longzhiteng2010@163.com
}

Received 29 February 2016; accepted 25 March 2016; published 28 March 2016

Copyright (C) 2016 by author and Scientific Research Publishing Inc.

This work is licensed under the Creative Commons Attribution International License (CC BY). http://creativecommons.org/licenses/by/4.0/

(c) (i) Open Access

\begin{abstract}
As new internet technology rapidly develops today, the global economy integration becomes closer, and business model also emerges endlessly. Crowdsourcing has been appeared. From wisdom crowdsourcing that improves the efficiency of the enterprise innovation to now the combination of crowdsourcing and various industries, the form of the crowdsourcing becomes more and more. Crowdsourcing greatly blurs the organizational boundaries of the enterprise, and enhances the consciousness of the individual, and promotes the effective use of social idle resources, making further improve the social welfare. The enterprise needs to use crowdsourcing to improve open innovation process, and network public use crowdsourcing to enrich their lives and works. Crowdsourcing will continue to optimize the efficiency of the enterprise service and the efficiency of the society.
\end{abstract}

\section{Keywords}

Wisdom Crowdsourcing, Crowdsourcing Logistics, Shared Economic, Social Welfare

\section{Introduction}

In the book of The nature of the enterprise Ronald H. Coase Pointed out that: The existence of the enterprise is to minimize the cost and permit someone who is authority (an "enterprise") to Control all resources, so as to save some markets running costs. When there is an enterprise, a series of factors of production is the internalization, thus this greatly reduces the number of contract, and it leads to less cost. Nowadays with the rapid development of the Internet of the new economy, the enterprise expands its boundary, and many aspects of the enterprise such as research and production, sale, transport costs become more and more big. With the flattening of the Internet, the distance of enterprises and consumers is becoming closer. This paper tells us that in order to further reduce costs and close to the consumer, the enterprise continues to use the resources of external (out of the film) 
to service for the company. This form calls crowdsourcing. The form of crowdsourcing can apply to all industries in the near future. It is constantly changing the operation of the enterprise form, at the same time in full use of social idle resources, to maximize the social utility.

\section{Crowdsourcing Overview}

\subsection{The Definition of Crowdsourcing}

Jeff Howe put forward the definition of crowdsourcing: Enterprise assigns the missions that should be performed by internal staff of the film to the network public groups to complete [1]. The public voluntary to participate in the activities of collaboration through computer communication technology in the mass collaboration, and this kind of form is relatively loose. What's more, Demil and Lecocq put forward the concept of "The market governance" to analysis the mode of the internet crowdsourcing. They consider that the market governance don't have the formal order of the film, Also do not have the strong social control that network structure have. The market governance in terms of formal and informal control are weak [2]. The public decide to whether to participate in, when and what kind of way of participation in the internet crowdsourcing. Wen-hua liu pointed out that Internet crowdsourcing is that enterprise subcontracts work tasks to the public through the Internet platform to finish the work as soon as possible. The essence of which is to make the contractee, the platform, the outsourcee and stakeholders to communicate with each other, forming a whole efficient production organization structure [3]. Grier considered that the definition of crowdsourcing is using the Internet to hire workers scattered to service for the enterprise [4].

With the development of Internet, the development of the Internet of things are changing quickly. Especially with the development of E-business, the o2o business model developed rapidly. The o2o (online to offline) business means that the consumers choose or reserve merchandise online, and buy merchandise offline. This model rapidly changes people's life and consumption habits. The original form of crowdsourcing is wisdom crowdsourcing. Wisdom crowdsourcing means that the public contribute their wisdom in the research and development phase of the enterprise. In this condition the model of crowdsourcing is expending, from wisdom crowdsourcing to varieties of business model, to continuously reduce the enterprise cost, to improve social welfare.

\subsection{From Outsourcing to Crowdsourcing}

Firstly there are some similarities between crowdsourcing and outsourcing: Crowdsourcing and outsourcing both rely on the external forces to finish the task, organizational boundaries of the company are no longer limited within the company. Sometimes when the task can't be finished or can be finished but expensive, we can use crowdsourcing or outsourcing to finish the task efficiently, and at the same time using crowdsourcing or outsourcing can save the company resources, so as to allow the company to focus on the part of the most core competitiveness. The reason of crowdsourcing or outsourcing, to some extent, is that organization also relies on external resources. These resources include not only the tangible things like land, capital or specific products, but also the intangible resources such as knowledge, creative.

Secondly crowdsourcing and outsourcing also have the very big difference: In this era of Internet development becoming more and more flat, each person's self-consciousness is more and more strong, outsourcing seems to become crowdsourcing when the outsourcee are public. But in fact the difference is very big: Outsourcing is what the enterprise gives the part which is no competitive in the company to the external to finish, enabling the enterprise to focus on their core competitiveness. The model of crowdsourcing, to some extent, can enhance the core competitiveness of enterprises, it is an effective supplement to the core competitiveness. And outsourcing is the relationship between organization and the organization, and crowdsourcing is the relationship between the organization and individual. Outsourcing emphasizes the specialization of operation, and crowdsourcing emphasize individual independence cross-border collaboration.

\subsection{Crowdsourcing Combination Form in the Internet Age}

\subsubsection{Traditional Forms of Crowdsourcing}

From Howe put forward the concept of crowdsourcing in 2006 for the first time to now, the crowdsourcing has had great application and development in the field of business. Crowdsourcing, which is based on Internet technology, links together the resources and talents people all over the world through the network terminal (Figure 1). 


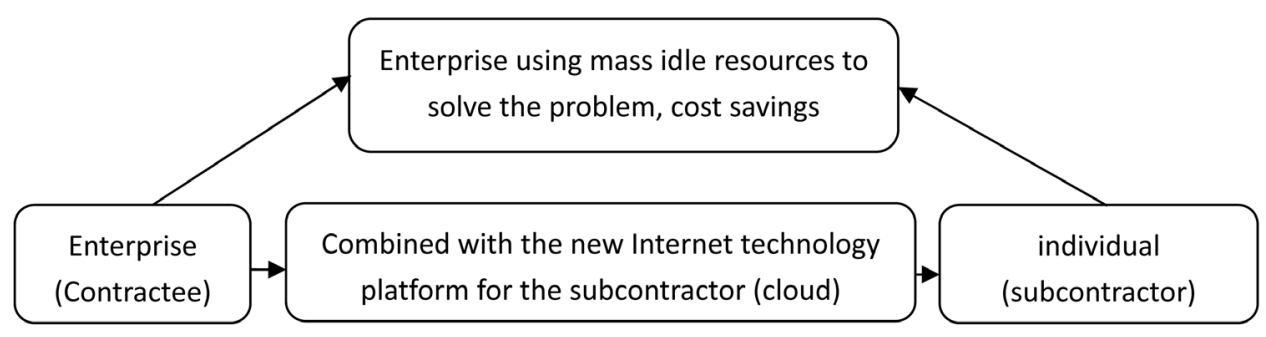

Figure 1. The form that crowdsourcing is.

It can use powerful and complex human resource network out of the enterprise, and realize the advantages of network public diversification and individuation. So it attracts more and more enterprises' attention.

Procter \& Gamble Company was the first company who applied the Internet crowdsourcing to it's global strategy, and made a great success. then many multinational companies such as L'Oreal, IBM, also applied the Internet crowdsourcing model to their global strategies. At the same time, not only large multinational companies abroad, but also some large domestic companies actively try Internet crowdsourcing operation pattern, such as Sogou, baidu, youku etc. InnoCentive is representative in the companies who provide the service that crowdsourcing can be implemented. Some companies such as Dupont, Boeing and Procter \& Gamble release the problem to www.innocentive.com, the global talent persons solve the problem together through the form of crowdsourcing. Then companies will make full use of social idle human resources and intellectual resources, and it saves the product research and development costs, and it shortens product development cycle. The rapid development of Internet makes the crowdsourcing model permeates into our life quickly.

We can see that the development of the traditional form of crowdsourcing is primarily a crowdsourcing ideas of wisdom. it mainly focuses on the research and development of the enterprise. Enterprise can understand consumers, capture the needs of the consumers with the fastest speed and minimum cost. And it can use the public's collective intelligence to greatly cut down the research and development costs of enterprises.

\subsubsection{The Expanding of Crowdsourcing Form}

In recent two years the software with taxi like Uber, DiDi quickly spreads the Chinese market, grabing some businesses of the taxi. Great changes have taken place in the way people travel. Uber's and DiDi's strategies are both to make full use of the new Internet technology and social idle resources of a large number of cars (Figure 2).

As a third party who connect the driver and the passenger, The companies themselves like Uber and DiDi do not provide a taxi service, Only do they assign the task to the vehicle idle car or taxi. This greatly reduces the operating costs of the companies. We can imagine: If the two companies have their own proprietary teams, There will be a huge increase costs because they must pay the team for their services. the model that Uber and DiDi use the individual drivers' spare resources is the use of crowdsourcing form in the taxi industry. What's more, this crowdsourcing form in the field of o2o continues to power. the application of the crowdsourcing model like Uber and DiDi to the impact of the new technology of the Internet era is not only limited to the taxi industry, what it brings us is actually the power of crowdsourcing. The power is great. After Uber the crowdsourcing model quickly spread many technology companies. When this model is applied to the logistics industry, it becomes present popular crowdsourcing logistics or the crowdsourcing micro logistics. The typical company who applied this model in china is the company named "Aixianfeng" who develops rapidly.

“Aixianfeng”, Founded in 2014, has accumulated more than 5 million users up to July 2015, and the number of convenience stores who cooperated with him reaches to more than 10 thousand. The turnover of each month are more 100 million yuan. The company presents the explosive growth [5].

From the collective wisdom crowdsourcing which is derived from the open source movement of dynamic network to logistics combined with personal crowdsourcing, the combination of crowdsourcing and business is more and more widely. From within the company to outsourcing to crowdsourcing, the company's organizational boundaries are more and more widely. New business patterns emerge in endlessly in this condition. The development of new technology promotes the development of crowdsourcing. The crowdsourcing promotes the social idle resources fully utilized, and this makes us gradually step into a new era of Shared economic. 


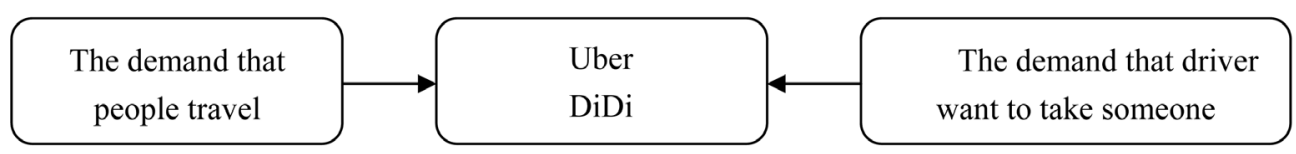

Figure 2. How crowdsourcing apply to the the software with taxi like Uber, DiDi.

\section{The Reason Why Crowdsourcing Is Expanding in the Internet Age}

Crowdsourcing is the product of the interaction between enterprises and individuals in the Internet age. So we explore the reason of crowdsourcing's foundation in two aspects: from enterprise to individual.

\subsection{The Traditional Collective Wisdom Crowdsourcing Motives}

From the enterprise level, Ma Wei et al. pointed out: because of the users' circumstance and demand information is always very subtle, tremendous and changeable, if enterprise wants to win the competition in the environment, it needs have a particularly strong innovation ability, and it needs the external stimulation of intellectual resources and impact. If not, it will fail in the competition. So the crowdsourcing as the new trend of innovation is especially popular to many companies [6]. Xiao Long points out: Enterprise innovation in many cases suffered bottleneck constraints is one of the very important reasons why crowdsourcing rises [7]. The company's mission is to increase all the company's shareholder values through the steady growth of profit of the company. Enterprises most worry about that due to their own innovation ability which is insufficient, their growth are stagnant, and gradually lose industry leading position. The reason why some innovative companies can go beyond the original industry and replace it is that their own innovation strength is big enough. That prompts that the enterprise must seek more diverse channels and low cost of innovation, and finally promotes the development of crowdsourcing.

The reason why the public participate in crowdsourcing can be separated in two parts:

Internal cause and external cause. The internal cause includes individual interest, the satisfaction of internal, the promotion of capability and so on. Strong creative people tend to be very good at self-motivation. These people prefer to listen to inner motivation. Li Yin et al. considered that the reason why many people participant in crowdsourcing was that they are interested in them. Its purpose was often the non-commercial [8]. Qiu-yan Zhong. et al. through the empirical pointed out: Internet users in China pay attention to the parts like the funny and affirmation of the self when they participant in crowdsourcing. The individuals who participate in crowdsourcing not only want to contact the product in advance, but also want to express their value proposition through participating in crowdsourcing. At the same time they can show their way of life, and finally satisfy their psychological needs [9]. Daren C. Brabham investigated the 651-member participation motives on the site of Istockphoto, and the results indicated that the primary motivation they were involved in is to learn new knowledge and skills. For the extrinsic motivation, Xi-lai Wang et al. pointed out, the reason why the public participation in crowdsourcing is that they can get extra pay in their spare time, and the pay will be more if they can provide more professional skills [10]. Lakhani \& Wolf investigated the men who participate in crowdsourcing in the site of Sourceforge, they found that a third of the respondents said that an important reason for them to join the community is economic factor. It is thus clear that monetary compensation is an important reason of crowdsourcing extensive development.

In addition to the above reasons, the reason why the public participate in crowdsourcing includes to boring to kill time, meeting new people, and to promote mutual cooperation. Bernardo A Huberman investigated the men who participation in crowdsourcing in the site of YouTube, and he found that to attract attention was also a driving force of the people involved in crowdsourcing.

\subsection{The Motivation That Crowdsourcing Is More and More Popular}

Along with the development of the Internet electric business, the development of logistics has become a new normal. With the speeding up of the new technology upgrade, new business models emerge in endlessly. In recent years the development of the o2o in all fields quickly spread all walks of life. The essence of o2o is online and offline connections and integration of social resources. In this context, the model of crowdsourcing is gradually accepted and used by enterprises and individual.

From the collective wisdom crowdsourcing which is applied in the research and development of the enterprise 
to the taxi crowdsourcing and logistics crowdsourcing nowadays, crowdsourcing has become a kind of brandnew concept which is changing our life. On one hand this change is ascribed to the rapid development of the new technology of Internet of things. Because it makes the connections between people more convenient and accurate. Technology development is the precondition of crowdsourcing extension. On the other hand, as information becomes completely Social idle resources gradually get people's attention. Enterprises can save their resources and cost through the crowdsourcing, while the public leisure resources can increase in value in the form of crowdsourcing. So that finally it can improve overall social welfare.

\section{The Risk of Crowdsourcing}

\subsection{The Risk of Traditional Forms of Crowdsourcing}

The lack of a comparatively clear contract constraint in traditional forms of crowdsourcing, which often happened in the condition that crowdsourcing is applied in the research and development of the enterprise, is likely to cause a loss of intellectual property rights and make the enterprise suffer losses. The theory of open innovation point out: Intellectual property rights disputes will inevitably become the barriers between enterprise and knowledge providers [11]. The enterprises' internal staffs also are likely to use the crowdsourcing model to service other enterprises who are competing with the company. This will further bring the hidden trouble of the intellectual property rights to the enterprise. Crowdsourcing is an innovation activities under the multiple and open environment, so that in such cases the ownership of the product is very complicated for crowdsourcing. In the condition that enterprises lack protection of consciousness and measures of intellectual property rights from time to time, it is easy to cause disputes. And other scholars believe that crowdsourcing might lead to ethical and legal risks.

\subsection{The Risk of Crowdsourcing in Recent Years}

The recent emergence of the combination of crowdsourcing and taxis and logistics has a subversive influence to the modern business model. But due to the short development time, this model also has great risks. For example, for crowdsourcing logistics, although crowdsourcing logistics look more handsome in the future, it needs large data capacity, and the control ability currently has not been solved well. For example, "Renren express", as a very popular company in China, had been halted in many places in China because of violation of the relevant provisions and to let the cat out of the user information. In the other hand, from the point of view of the user, faced with no unified dress and no express specialized delivery vehicles, this is a security issue. Especially under the condition of China who haven't established credit system, we need to rely on the rule of law to deliver it.

\section{Some Suggestions of the Development of Crowdsourcing}

The model of traditional forms of crowdsourcing is comparatively mature, but the recent emergence of the combination of crowdsourcing and taxis and logistics is not enough mature, and it is a new concept and trend. if crowdsourcing wants to service the society in the condition that development of science and technology is rapid and system is not perfect, the government needs to include various forms of innovation with more tolerant attitude, at the same time, strengthen the establishment of a national credit system. And enterprises need to be more open attitude using new technology to develop crowdsourcing, and use constant innovation to reduce the cost, and strictly observe the relevant regulations of the countries at the same time. Individuals must understand crowdsourcing which is the trend that has a strong independent consciousness, realize ours' own value proposition through crowdsourcing with ownership, and use our idle resources to achieve greater value. Eventually Social welfare will increase.

\section{The Future Development of Crowdsourcing}

The development of the Internet is more and more fast. The big data age is coming. The new technology and new economy update with geometrical level. Information is more and more completely. The world becomes more and more like a global village. Consumers' growing self-awareness is more and more strong. The form of crowdsourcing which connects enterprises and individuals will be more and more popular for enterprises and the public. Crowdsourcing model provides a very strong driving force for enterprises' innovation, continuously 
breaks the boundaries of the enterprise, and it can promote collaborative innovation that individuals who are capable and companies in many businesses which are cross-industry and cross-regional, and this will greatly promote the industry's innovation capability and reduce the cost of innovation. For individuals, crowdsourcing provides convenience for entrepreneurship and innovation.

The task type the crowdsourcing model can apply is rich, it not only includes research and development for technical personne, but also includes the task of service class for the general public. From the point of the way the public who participate in, the participation of those who involved in the laborer of crowdsourcing will be more fair. And at the same time the laborer of crowdsourcing can choose tasks flexibly according to their own situation and schedule. From the point of society, crowdsourcing will supply the open sharing of information resources and innovation. And it can stimulate the society main body participation enthusiasm in the field of production and life, and at the same time it can greatly improve enterprises' service ability which will be more diversified and efficient.

From the collective wisdom crowdsourcing to logistics combined with personal crowdsourcing, the crowdsourcing model is combined with all walks of life in the age of the Internet. With the development of technology, crowdsourcing has increasingly become a possibility. Crowdsourcing bring enterprise continuously cost savings and constant innovation. And it brings the individual a more and more personalized world.

\section{Conclusion}

Crowdsourcing is a new trend. By comparing the past and present development of crowdsourcing, this paper has offered new vision of crowdsourcing: crowdsourcing not only can apply to research and development of an enterprise, what's more, it can apply to all industries. So that it can produce more and more new business model. Finally enterprises' cost will reduce. The idea of individual will come true. The social welfare will increase. However, there exists risk because of imperfect information, so we should be patient for the development of crowdsourcing. We will see that crowdsourcing will change our lives deeply in the near future.

\section{References}

[1] Ajzen, L. (2005) The Theory of Planned Behavior. Organizational Behavior and Huaman Decision Process, 12, 231 242.

[2] Demil, B. and lecocq, X. (2006) Neither Market nor Hierarchy nor Network: The Emergence of Bazaar Governance. Organization Studies, 27, 1447-1466. http://dx.doi.org/10.1177/0170840606067250

[3] Liu, W.H. (2009) The Economics Parsing of Crowdsourcing. New Economy Weekly, 6, 91-95.

[4] Grier, D.A. (2011) Not for All Markets. Computer, 44, 6-8. http://dx.doi.org/10.1109/mc.2011.155

[5] Kong, W,S. (2015) Aixuanfeng: How to Play the Crowdsourcing Logistics. China Economic Information, 16, 70-71.

[6] Ma, W., et al. (2008) The Change from Outsourcing to the Business Model of Crowdsourcing and Enlightenment. Commercial Economic Research, 1, 13-14.

[7] Long, X. (2007) From Outsourcing to Crowdsourcing. Commercial World: China Business Review, 4, 96-99.

[8] Yin, L. and Zeng, Y.H. (2009) Consumer Demand Upgrading, Prosumer and Market Boundary. Journal of Shandong University (Social Science Edition), 5, 18-27.

[9] Zong, Q.Y., et al. (2011) An Empirical Study of the Behavior of the User Community Continue to Participate in Crowdsourcing. Journal of Dalian University of Technology: (Social Science Edition), 1, 1-6.

[10] Wang, L.X., et al. (2011) Crowdsourcing: Enterprise Innovation Method of Democratization. Enterprise Vitality, 4, 7071.

[11] Ding, M. and Eliashberg, J. (2002) Structuring the New Product Development Pipeline. Management Science, 48, 343363. http://dx.doi.org/10.1287/mnsc.48.3.343.7727 